\title{
Titanium Alloys: Processing and Properties
}

\author{
Martin Bache (D)
}

check for updates

Citation: Bache, M. Titanium Alloys: Processing and Properties. Metals 2021, 11, 1426. https://doi.org/ $10.3390 /$ met11091426

Received: 6 July 2021

Accepted: 18 July 2021

Published: 9 September 2021

Publisher's Note: MDPI stays neutral with regard to jurisdictional claims in published maps and institutional affiliations.

Copyright: (c) 2021 by the author. Licensee MDPI, Basel, Switzerland. This article is an open access article distributed under the terms and conditions of the Creative Commons Attribution (CC BY) license (https:// creativecommons.org/licenses/by/ $4.0 /)$.
Institute of Structural Materials, Swansea University, Swansea SA1 8EN, UK; m.r.bache@swansea.ac.uk

The invited review paper to accompany this special issue, authored by Williams and Boyer [1], provides a comprehensive historical appraisal for the application of titanium alloys in engineering components, a description of the current "state of the art" and a view to the future for titanium alloys within the aerospace sector in particular. Given their considerable commercial experience in the gas turbine and airframe industries respectively, the authors are fully cognisant of the financial barriers placed on the selection of titanium alloys for engineering applications. However, this perception of titanium as a high cost material can often be countered by the excellent fatigue strength, corrosion resistance and weight saving characteristics on offer, particularly when considered for components within high-performance gas turbines and rocket engines. A wide range of titanium processing techniques are introduced within the paper, including traditional melt/cast and wrought technologies, super plastic forming and the more recent employment of powder-based additive manufacturing. The control of the two basic allotropic $\alpha$ and $\beta$ phases and the subsequent classification into five major classes of conventional alloy is described before introducing the field of intermetallic titanium systems. The latter offer opportunities to replace relatively dense nickel-based components for hot section applications above $700{ }^{\circ} \mathrm{C}$; however, their relatively low ductility at room temperature is recognised as a limiting factor. In conclusion, this paper should be considered as a seminal literature review of titanium alloy development and application.

The additional 14 papers all compliment the processing-properties theme of the special volume.

Elements of fundamental metallurgy and microstructural evolution are described for highly specialised titanium-based laser welded joints, shape memory alloys, additive manufactured parts and biomedical Ti-Ni alloys (Abdollahi et al. [2], Huang et al. [3], Panin et al. [4], Cascadan and Grandini [5], respectively). Choe et al. [6] describe grain boundary TiFe precipitation in a $\alpha+\beta$ alloy and the employment of isothermal aging as a mechanism for controlling subsequent strength. Reliant on high quality empirical study, all of these papers emphasise the relationship between mechanical properties, development of distinct microstructures and the role of interstitial elements. In selected cases they also serve as a reminder of the wider applications for titanium beyond the aerospace sector.

Various papers specifically focus on the fundamental mechanisms controlling the "cold dwell" response of near $\alpha$ alloys [7]. These publications are highly pertinent given the current interest around a recent in-service dwell-related failure of a Ti 6/4 fan disc [8]. The development of textured microstructures and the relationship to fatigue crack initiation via quasi-cleavage faceting is described by Germain et al. [9]. The formation of inhomogeneous microstructures through highly localised variant selection during the forging process is highlighted as a subsequent driver for stress redistribution during loading between "weak" and "strong" regions of the material. Their alloy of interest, Ti 6242, has long been noted as a "dwell sensitive" variant, with a comprehensive study documenting many aspects of cold dwell performance published by Ghosh et al. [10]. It is interesting to note that Ti 6/4, being a popular choice for fan and compressor applications since the 1960s, has developed a longstanding reputation as a dwell "insensitive" alloy. However, the recognition that "microstructurally textured regions" (MTRs) or "macrozones" can also be retained in 
Ti 6/4 forgings and go on to promote an associated dwell debit [11] has highlighted a need to revisit this perception. Computer modelling of such adverse microstructures is included in this special volume by Ma and Truster [12]. Based on crystal plasticity, the success of the models are (somewhat naturally) shown to be sensitive to the description of representative microstructures. Regardless, the stress redistribution process and control from crystallographic orientations relative to loading is clearly predicted. Fundamental mechanical properties under cyclic and dwell loading configurations are considered by Bache et al. [13], concentrating on low and high cycle fatigue scenarios for a novel near $\alpha$ alloy. Ti 407 was developed for containment applications due to a high inherent ductility; however, it also serves as a model for dwell behaviour. Emphasis was placed on crack initiation and faceting mechanisms.

At the opposite end of the fatigue process, the paper from Renon et al. [14] concentrates upon the damage tolerant characteristics of conventional forms of Ti 6/4 and Ti 6/4 ELI (extra low interstitial variant) subjected to various heat treatments. A comprehensive database is presented to describe constitutive behaviour and continuum fatigue crack growth. Optical fractography and 3D profilometry are used to good effect to illustrate the complex, tortuous fracture path taken by cracks generated in relatively large grained lamellar microstructural forms.

Su et al. [15] also concentrated upon crack propagation behaviour, on this occasion under dwell waveforms in commercially pure titanium as a function of temperature, performing their test matrix up to $300^{\circ} \mathrm{C}$. The concept of "dwell" effects under this scenario is slightly different to that described above relating to life to first crack and fatigue strength Focusing solely on damage tolerance, i.e., Stage II or "Paris" crack growth, the imposition of dwell under these circumstances controls time dependent creep mechanisms at the crack tip together with environmental enhancement on crack growth rates through oxidation.

Four papers can be collated around the theme of metal forming. Returning to the topic of cost effectiveness, Pope and Jackson expand on a process developed for the production of near net shape forged titanium products-field-assisted sintering technology (FAST). The environmental benefits of employing titanium powder as a basis for sintering of high integrity, functionally graded preforms and associated mechanical flow properties are described. Looking to the future, the FAST process offers greater sustainability and more efficient use of titanium resources given that machining revert material can be employed as an alternative source stock [16]. Flow stress characterisation by Yang et al. [17], again employs compression testing but this time employing a more traditional wrought product, albeit a novel metastable $\beta$ alloy, as the vehicle of interest. Yan et al. [18] then consider the sensitivity of a near $\alpha$ sheet product to grain size and pre-forming annealing heat treatments with an eye to super plastic forming capability. Finally amongst the forming contributions, Zhang et al. [19] present a detailed study of hot compression testing applied to a novel particle reinforced titanium composite system, aiming to gain a fundamental understanding of the potential modifications to flow behaviour due to the presence of a reinforcing whisker phase.

Funding: This editorial received no external funding.

Acknowledgments: As Guest Editor, my retrospective thanks go out to all of the authors for contributing their high quality manuscripts to this special volume. Finally, thank you to the team at the Metals editorial office for their assistance and the numerous individuals who helped review the manuscripts.

Conflicts of Interest: The author declares no conflict of interest.

\section{References}

1. Williams, J.C.; Boyer, R.R. Opportunities and Issues in the Application of Titanium Alloys for Aerospace Components. Metals 2020, 10, 705. [CrossRef]

2. Abdollahi, A.; Ahnaf Huda, A.S.; Kabir, A.S. Microstructural Characterization and Mechanical Properties of Fiber Laser Welded CP-Ti and Ti-6Al-4V Similar and Dissimilar Joints. Metals 2020, 10, 747. [CrossRef] 
3. Huang, T.-S.; Ou, S.-F.; Kuo, C.-H.; Yang, C.-H. Effects of Thermomechanical Treatment on Phase Transformation of the Ti ${ }_{50} \mathrm{Ni}_{49} \mathrm{~W}_{1}$ Shape Memory Alloy. Metals 2020, 10, 527. [CrossRef]

4. Panin, A.; Kazachenok, M.; Perevalova, O.; Martynov, S.; Panina, A.; Sklyarova, E. Continuous Electron Beam Post-Treatment of EBF $^{3}$-Fabricated Ti-6Al-4V Parts. Metals 2019, 9, 699. [CrossRef]

5. Cascadan, D.; Grandini, C.R. Effect of Oxygen in the Structure, Microstructure and Mechanical Properties of Ti- $x$ Ni $(x=5,10,15$ and $20 \mathrm{wt} \%$ ) Alloys. Metals 2020, 10, 1424. [CrossRef]

6. Choe, H.-J.; Won, J.W.; Hyun, Y.-T.; Lim, K.R.; Yoon, S.-Y. TiFe Precipitation Behavior and its Effect on Strengthening in Solution Heat-Treated Ti-5Al-3.5Fe During Isothermal Aging. Metals 2018, 8, 875. [CrossRef]

7. Bache, M.R. A review of dwell sensitive fatigue in titanium alloys: The role of microstructure, texture and operating conditions Int. J. Fatigue 2003, 25, 1079-1089. [CrossRef]

8. BEA2017-0568. Investigation Report: Accident to the AIRBUS A380-861 Equipped with Engine Alliance GP7270 Engines Registered F-HPJE Operated by Air France on 30 September 2017 in Cruise over Greenland (Denmark); Bureau d'Enquêtes et d'Analyses Pour la Sécurité de L'aviation Civile: Le Bourget, France, 2020.

9. Germain, L.; Samih, Y.; Delaleau, P.; Gilgert, J.; Gey, N. Analysis of Cold Dwell Fatigue Crack Initiation Site in a $\beta$-Forged Ti-6242 Disk in Relation with Local Texture. Metals 2020, 10, 951. [CrossRef]

10. Ghosh, S.; Mills, M.; Rokhlin, S.; Sinha, V.; Soboyejo, W.; Williams, J. The Evaluation of Cold Dwell Fatigue in Ti-6242; Final Report DOT/FAA/AR-06/24; National Technical Information Service (NTIS): Springfield, VA, USA, 2007.

11. Venkatesh, V.; Noraas, R.; Pilchak, A.; Tamirisa, S.; Calvert, K.; Salem, A.; Broderick, T.; Glavicic, M.G.; Dempster, I.; Saraf, V. Data Driven Tools and Methods for Microtexture Classification and Dwell Fatigue Life Prediction in Dual Phase Titanium Alloys. In Proceedings of the 14th World Conference on Titanium, Nantes, France, 10-14 June 2019; Volume 321, p. 11091. [CrossRef]

12. Ma, R.; Truster, T.J. A Hierarchical Multiscale Modeling Investigation on the Behavior of Microtextured Regions in Ti-6242 $\alpha / \beta$ Processing. Metals 2019, 9, 233. [CrossRef]

13. Bache, M.; Davies, H.; Davey, W.; Thomas, M.; Berment-Parr, I. Microstructural Control of Fatigue Behaviour in a Novel $\alpha+\beta$ Titanium Alloy. Metals 2019, 9, 1200. [CrossRef]

14. Renon, V.; Henaff, G.; Larignon, C.; Perusin, S.; Villechaise, P. Identification of Relationships between Heat Treatment and Fatigue Crack Growth of $\alpha \beta$ Titanium Alloys. Metals 2019, 9, 512. [CrossRef]

15. Su, C.-Y.; Zhou, C.-Y.; Lu, L.; Li, J.; Sun, P.-Y.; He, X.-H. Effect of Temperature and Dwell Time on Fatigue Crack Growth Behavior of CP-Ti. Metals 2018, 8, 1031. [CrossRef]

16. Weston, N.S.; Jackson, M. FAST-forge of Titanium Alloy Swarf: A Solid-State Closed-Loop Recycling Approach for Aerospace Machining Waste. Metals 2020, 10, 296. [CrossRef]

17. Yang, Q.; Ma, M.; Tan, Y.; Xiang, S.; Zhao, F.; Liang, Y. Initial $\beta$ Grain Size Effect on High-Temperature Flow Behavior of Tb8 Titanium Alloys in Single $\beta$ Phase Field. Metals 2019, 9, 891. [CrossRef]

18. Yan, B.; Li, H.; Zhang, J.; Kong, N. The Effect of Initial Annealing Microstructures on the Forming Characteristics of Ti-4Al-2V Titanium Alloy. Metals 2019, 9, 576. [CrossRef]

19. Zhang, C.; Lian, Y.; Chen, Y.; Sun, Y.; Zhang, S.; Feng, H.; Zhou, Y.; Cao, P. Hot Deformation Behavior and Microstructure Evolution of $\mathrm{a} \mathrm{TiB}_{w} /$ Near $\alpha$-Ti Composite with Fine Matrix Microstructure. Metals 2019, 9, 481. [CrossRef] 